\title{
Students' Math Self-Concept, Math Anxiety, and Math Achievement: The Moderating Role of Teacher Support
}

\author{
Satoshi Oda ${ }^{1}$, Chiaki Konishi ${ }^{1}$, Takashi Oba ${ }^{3}$, Tracy K. Y. Wong ${ }^{1}$, Xiaoxue Kong ${ }^{2} \&$ Chloe St. Onge-Shank ${ }^{1}$ \\ ${ }^{1}$ Department of Educational and Counselling Psychology, McGill University, Montreal, Quebec, Canada \\ ${ }^{2}$ Department of Psychology, Neuroscience \& Behaviour, McMaster University, Hamilton, Ontario, Canada \\ ${ }^{3}$ Department of English Language and Communication, Showa Women's University, Tokyo, Japan \\ Correspondence: Tracy K. Y. Wong, Department of Educational and Counselling Psychology, McGill University, \\ Montreal, Quebec, Canada.
}

Received: January 2, 2021

Accepted: February 11, 2021

Online Published: March 4, 2021

doi:10.20849/jed.v5i1.866

URL: https://doi.org/10.20849/jed.v5i1.866

\begin{abstract}
This study explored the moderating roles of teacher instrumental and emotional support on the association between students' math anxiety/math self-concept and math achievement. Participants included 21,544 Canadian students aged 15 years (10,943 girls) who participated in the 2012 Program for International Student Assessment. Results indicated that instrument support and emotional support were positively associated with math achievement. A significant moderation effect was evident between instrumental support and math anxiety; higher levels of instrumental support were associated with higher math achievement at low levels of math anxiety. Emotional support did not interact with math anxiety or math self-concept. The present findings highlight the importance to consider not only individual factors (i.e., math anxiety and math self-concept) but also the role of teacher support in supporting math achievement.
\end{abstract}

Keywords: math anxiety, math self-concept, instrumental support, emotional support, math achievement

\section{Introduction}

Math achievement forecasts not only students' academic success in Language (Duncan et al., 2007) and Science (Anderton, Joyce, \& Hine, 2017; Joyce, Hine, \& Anderton, 2017), but also their social-emotional well-being (Romano, Babchishin, Pagani, \& Kohen, 2010), health-related decisions (Reyna, Nelson, Han, \& Dieckmann, 2009), and future socio-economic status (Ritchie \& Bates, 2013). Given its importance, research efforts have been dedicated to identifying factors that could potentially promote or hinder math achievement. Previous research has primarily explored individual factors such as sex, motivation, and academic self-concept; more recently, researchers have pointed a need to also account for the role of teacher support (Federici \& Skaalvik, 2014a; Yu \& Singh, 2018). The goal of the present study was thus to bridge the existing literature on teacher support with the established literature on individual characteristics. Specifically, this study examined the extent to which student-related factors (i.e., math anxiety and math self-concept) interact with teacher support (i.e., academic and emotional support) to facilitate or impede math achievement. Math anxiety and math self-concept were selected not only because they are exemplars of individual factors that affect math achievement (Foley et al., 2017; McDonough \& Ramirez, 2018), but also because they respectively predict this learning outcome in the negative and positive direction (Chen, Yeh, Hwang, \& Lin, 2013; Núñez-Peña, Suárez-Pellicioni, \& Bono, 2012; Parker, Marsh, Ciarrochi, Marshall, \& Abduljabbar, 2014; Wu, Barth, Amin, Malcarne, \& Menon, 2012). Hence, they serve as interesting contexts to understand the moderating effects of teacher support. Teacher support was exemplified by both instrumental and emotional support because the former orients towards learning and understanding whereas the latter orients towards the affective component of learning. By positioning instrumental support and student-teacher relationship as juxtaposing moderators that might substantiate or weaken the association between student-related factors and math achievement, this study would provide a different perspective to the literature that has mainly addressed teacher support as a direct predictor of math outcomes (e.g., Federici \& Skaalvik, 2014b). Practically, it would also inform educators regarding which type of student-teacher exchanges (i.e., in the forms of instrumental or emotional support) might be more appropriate in facilitating positive or mitigating the chance of poor learning outcomes. 


\subsection{Math Anxiety}

Math anxiety differs from trait anxiety as it reflects a sense of fear or apprehension towards situations that involve numbers, math, and mathematics calculations (Ashcraft \& Moore, 2009; Wu et al., 2012). Math anxiety is most prevalent among school-aged and college students (Maloney \& Beilock, 2012) and is often experienced during math class or math exams (Ashcraft \& Moore, 2009). Mathematically anxious students are less likely to enrol in and enjoy math courses, are less motivated to engage in math tasks (McDonough \& Ramirez, 2018), and are more likely to question the usefulness of math (Ashcraft \& Moore, 2009). Importantly, students who are anxious about math tend to demonstrate poorer performance on math achievement tests regardless of their grade-level (Núñez-Peña et al., 2012; Wu et al., 2012), and cultural background (OECD, 2013). To elucidate, results from the 2012 Program for International Student Assessment (PISA) indicated that, on average across 64 participating education systems, 15-year-old students with higher levels of math anxiety scored 29-point lower than their counterparts with lower levels of math anxiety (OECD, 2013). Further, a longitudinal study found that second-grade math anxiety was negatively associated with third-grade math applications (e.g., algebra, probability) among students with high working memory scores, controlling for initial reading, early numeracy and working memory (Vukovic, Kieffer, Bailey, \& Harari, 2013).

\subsection{Math Self-Concept}

Similar to math anxiety, math self-concept is also related to math achievement; this relation, however, is in the opposite direction. Math self-concept can be conceptualized as a dimension that falls under the broad construct of academic self-concept, which denotes an individual's knowledge and perceptions about him or herself and abilities within the academic realm (Brunner, Keller, Hornung, Reichert, \& Martin, 2009; Marsh, 1999). It differs from academic self-efficacy, which refers to an individual's self-perceived confidence to succeed at a given academic task (Bong \& Skaalvik, 2003). In other words, math self-concept reflects one's self-perceived ability in mathematical situations. Research consistently indicates that students who endorse a greater sense of math self-concept tend to perform better in math (Guo, Marsh, Parker, Morin, \& Yeung, 2015; Skaalvik \& Skaalvik, 2004). In corroboration, a longitudinal study involving more than 5,000 seventh graders found that math self-concept significantly predicted both math grades and standardized math test scores measured three years later, after controlling for the effects of math interest, grades and test scores measured at Time 1 (Marsh, Trautwein, Lüdtke, Köller, \& Baumert, 2005). In addition to math achievement, math self-concept is longitudinally related to interests in math (Marsh et al., 2005), Science, Technology, Engineering and Mathematics (STEM) course selection, and university entry (Marsh et al., 2005; Parker, Schoon, Tsai, Nagy, Trautwein, \& Eccles, 2012; Parker et al., 2014).

\subsection{Different Types of Teacher Support}

Previous studies investigating the motivational dynamics that underlie academic achievement have focused largely on students' differences in belief systems and abilities, such as academic self-concept and anxiety (Furrer \& Skinner, 2003; Federici \& Skaalvik, 2014a). More recently, researchers are becoming increasingly concerned with the importance of teacher support. When students experience high levels of teacher support, they tend to feel more accepted within the school (e.g., Ma, 2003; Osterman, 2000), demonstrate higher levels of interest and enjoyment towards their schoolwork (Hochweber \& Vieluf, 2018; Strati, Schmidt \& Maier, 2017), have greater expectancy for success in the classroom (Goetz, Lüdtke, Nett, Keller \& Lipnevich, 2013), and have better academic performance (e.g., Hochweber \& Vieluf, 2018). Broadly, teacher support can be distinguished into academic and emotional or affective support (Patrick, Ryan, \& Kaplan, 2007; Sakiz, Pape, Woolfolk-Hoy, 2012; Song, Bong, Lee, \& Kim, 2015). Academic support denotes not only teachers' provision of appropriate instructions and information, but also their use of modelling and scaffolding techniques to encourage student learning and progress (Patrick et al., 2007; Song et al., 2015). By contrast, emotional or affective support captures teachers' affective behaviours, such as when they express care or concern towards student well-being, as well as value and respect students as unique individuals (Konishi, Hymel, Zumbo, \& Li, 2010; Patrick et al., 2007; Sakiz et al., 2012).

In view that students have better math achievement when their teachers not only explain and connect math concepts effectively, but also support them in developing problem-solving skills, mathematical reasoning, and an understanding on the logical structure of math (Yu \& Singh, 2018), this study operationalized academic support as instrumental support. Indeed, instrumental support, which refers to assistance in problem solving through tangible and practical help or information (Federici \& Skaalvik, 2014b; Vendecandelaere et al., 2012), is in line with the pedagogy of conceptual teaching. Despite the importance of instrumental support in math learning, surprisingly few studies have examined it in relation to individual student characteristics. Emerging evidence nonetheless suggests that it has implications on student characteristics, such as perceived utility and intrinsic value of math (Federici \& Skaalvik, 2014b), tendency to seek for help in the math classroom to clarify 
understanding, amount of effort put forward to completing math tasks, and level of intrinsic motivation towards math activities (Federici \& Skaalvik, 2014a). In addition to student characteristics, instrumental support is also positively associated with math achievement (Tennant et al., 2015; Wong, Tao, \& Konishi, 2018). To the extent that students benefit more from instrumental support within the context of math learning, it is important to consider how it might interact with individual student characteristics to impact math achievement.

Students also benefit academically when they receive emotional support. A meta-analysis (189 studies) indicated that students across all grade-levels tended to have better academic achievement when they received high levels of emotional support, warmth, and acceptance (i.e., positive student-teacher relationship) from their teachers (Roorda, Jak, Zee, Oort, \& Koomen, 2017). The academic advantages associated with emotional support is also apparent within the math classroom. For instance, a longitudinal study indicated that students who moved from having supportive and caring elementary school teachers to less friendly middle school teachers had significantly lower math achievement (Midgley et al., 1989). By contrast, students who went from negative relations with elementary school teachers to positive relations with middle school teachers significantly improved math skills over the transition year (Midgley et al., 1989). Additionally, students who feel respected and encouraged by their math teachers tend to experience greater sense of class belonging, display higher enjoyment and demonstrate greater self-efficacy towards math tasks (Sakiz et al., 2012). In corroboration, a longitudinal study found that that first-grade teacher's emotional support positively predicted sixth-grade task persistence in math (Kikas \& Mägi, 2016). Despite this line of evidence, research that focuses specifically on the association between emotional support and math achievement is warranted in light of studies that have failed to find a significant direct association (Hindman, Skibbe, Miller, Zimmerman, 2010; Kikas \& Mägi, 2016).

\subsection{The Moderating Role of Teacher Support}

In view of the significant role that teacher support assumes in learning outcomes, there is a possibility that instrumental and emotional support would moderate the association between student learning-related characteristics (i.e., math self-concept and math anxiety) and math achievement. For example, the negative association between math anxiety and math achievement could be weakened when mathematically anxious students receive instrumental support from their teachers. Similarly, students with a low math self-concept might benefit academically when their teachers are sensitive to their needs. In this contention, a small but a growing body of evidence suggests that teacher support such as healthy student-teacher relationship might serve as a buffer between risk factors and student outcomes (Griggs, Gagnon, Huelsman, Kidder-Ashley, \& Ballard, 2009; Hamre \& Pianta, 2005; Loukas, \& Robinson, 2004; Konishi et al., 2010). For instance, a longitudinal study found that students with low effortful control and conflictual parent-child relationship at age 13 were protected from depression and misconduct five years later at age 18 if they had a positive relationship with their teachers (Wang, Brinkworth, \& Eccles. 2013). Another study indicated that students with poor family relations (i.e., a contextual risk-factor) were protected from conduct problems if they felt connected to adults in the school (Loukas, Roalson, \& Herrera, 2010). While this limited line of evidence demonstrates that teacher support is effective in moderating the association between student characteristics and student outcomes, it is important to note that these outcomes are often oriented towards students' social-emotional well-being (e.g., conduct problems). Thus, further research is necessary to determine whether the moderating effects of teacher support would also apply to academic outcomes (Rudasill, Gallagher, \& White, 2010; Wentzel, Russell, \& Baker, 2016).

Compared to emotional support, even less is known concerning the moderating role of specific forms of academic support. Indeed, extant studies that attended to academic outcomes have focused primarily on the moderating role of student-related characteristics, such as sex and learning-related cognitive competencies (e.g., effortful control; Gherasim, Butnaru, \& Mairean, 2013; Valiente, Swanson, \& Eisenberg, 2012) rather than teacher- or classroom-related characteristics. A handful of studies, however, suggested that academic support could also be an effective moderator. For instance, Hamre and Pianta (2005) found that primary students of less educated mothers (i.e., at risk for academic failure) performed at a level that was comparable to those with more educated mothers at the end of the school year if they were placed in a classroom that offered medium to high levels of instructional support (e.g., engaging students in academic discussion); by contrast, students whose mothers were less educated had significantly lower achievement if they received little instructional support. Lopez (2012) found that instructional support moderated the association between bilingual education and reading achievement among primary students. Given the lack of understanding on how different types of teacher support interact with student characteristics to promote math achievement among secondary students, further research on the matter is necessary. In particular, as extant studies have focused on preschool and primary students (e.g., Hamre \& Pianta, 2005; Lopez, 2012) despite that adolescents tend to show an academic downturn as they enter middle school (e.g., declining school engagement and doubting their ability to succeed) (Eccles \& Roeser, 2009), examining these associations among adolescents would be important. 


\subsection{The Present Study}

The present study aimed to address existing gaps in the literature surrounding the moderating role of teacher support on math self-concept and math anxiety by investigating sub-categories of support including instrumental support and emotional support (see Figure 1). Specifically, this study addressed the following questions: (1) To what extent are math anxiety, math self-concept and teacher support associated with math achievement?; (2) To what extent do instrumental and emotional support each moderate the association between math anxiety and math achievement?; and (3) To what extent do instrumental and emotional support moderate the association between math self-concept and math achievement?; Based on the reviewed literature, we hypothesized: (1) student characteristics and teacher support would predict math achievement; (2) students who were mathematically anxious would have better math achievement when they received instrumental and emotional support; and (3) students who had low math self-concept would have better achievement when they received instrumental and emotional support. Understanding whether and how instrumental support and emotional support moderate the juxtaposing roles of math anxiety and math self-concept on math achievement would inform intervention efforts to promote math achievement.

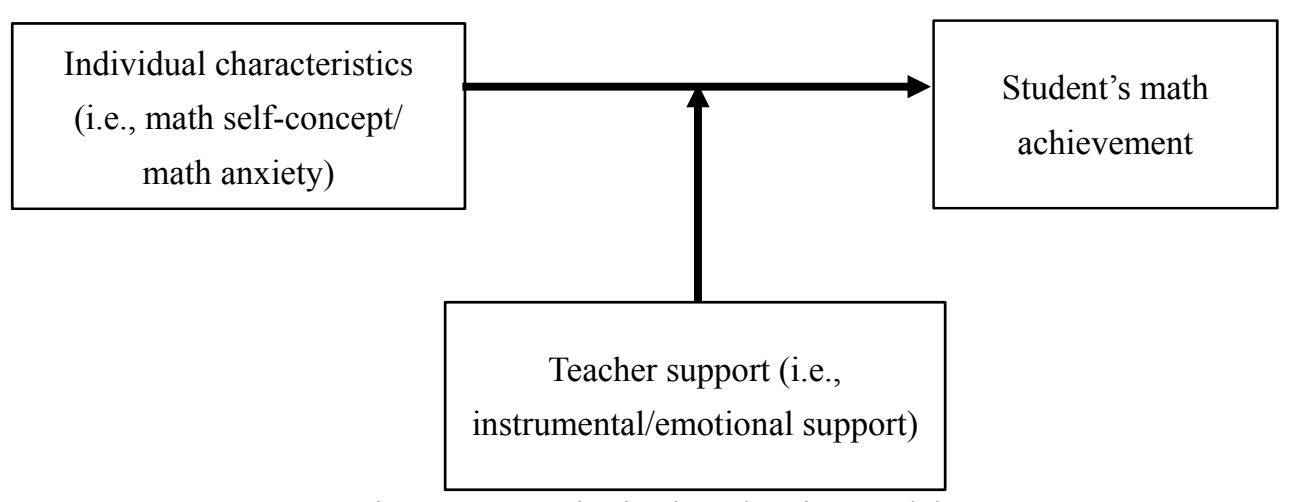

Figure 1. Hypothesized moderation model

\section{Method}

\subsection{Participants}

This study used a secondary database compiled by the Organization for Economic Co-Operation and Development (OECD, 2014) for the 2012 Program for International Student Assessment (PISA). Broadly, PISA aims to assess students' ability to use their reading, mathematical, and scientific knowledge to meet real-life challenges (OECD, 2013). All measures were developed through a rigorous process involving local and international item panelling, multiple pilot testing and reviews in efforts to ensure that their reliability and construct validity maintain across all participating countries. Items of each measure have also been scaled across these countries to create a composite score for each participant.

This study specifically employed the dataset involving Canadian students. Participants included 21,544 (10, 943 girls) 15-year-old Canadian students who participated in the 2012 PISA. As 35\% participants had missing data across all variables, they were removed from analyses, resulting in a final sample of 13,983 students ( 7125 girls).

\subsection{Measures}

In addition to demographic information such as countries and sex, five variables were considered in the current study, including standardized math achievement scores, math anxiety, math self-concept, instrumental support, and emotional support. All variables except math test scores were assessed with relevant measures from students' perspective. Responses pertaining to each measure were scaled across countries by PISA to construct a single score for each student.

Mathematics achievement scores. Math achievement was represented by a standardized score that participants received on the math portion of the PISA assessment. The test consisted of both multiple-choice and short-answer questions that evaluated mathematic reasoning, and content knowledge on quantity, uncertainty and data, change and relationships, and space and shape (OECD, 2013). Higher scores indicated higher achievement.

Math anxiety. Students' math anxiety was evaluated by five items such as "I often worry that it will be difficult for me in mathematics classes," "I get very nervous doing mathematics problems," and "I worry that I will get poor grades in mathematics." These items were rated on a 4-point Likert scale $(1=$ strongly agree to $4=$ strongly 
disagree); a higher score reflected higher levels of math anxiety. Cronbach's coefficient alpha for math anxiety was 87 .

Math self-concept. Students' sense of math self-concept was evaluated by five items such as "I am just not good at mathematics," "I learn mathematics quickly," and "I have always believed that mathematics is one of my best subjects." These items were rated on a 4-point Likert scale $(1=$ strongly agree to $4=$ strongly disagree $)$; a higher score indicated higher levels of math self-concept. Cronbach's coefficient alpha for math self-concept was .91.

Instrumental support. Students reported on the extent to which their math teachers provided instrumental support using four items, such as "My teacher provides extra help when needed," and "My teacher helps students with their learning." These items were rated on a 4-point Likert scale ( $1=$ strongly agree to $4=$ strongly disagree $)$; a higher score indicated higher levels of perceived instrumental support. Cronbach's coefficient alpha for instrumental support was .82 .

Emotional support. Students' perceived teacher emotional support was assessed by five items such as "Students get along well with most teachers," "Most teachers are interested in students' well-being," and "Most of my teachers really listen to what I have to say." These items were rated on a 4-point Likert scale $(1=$ strongly agree to $4=$ strongly disagree); a higher score reflected higher levels of relational support. Cronbach's coefficient alpha for emotional support was 85 .

\subsection{Analytical Plan}

To obtain a broad picture of the relations among the variables of interest, correlational analyses were first performed. Moderation analyses were conducted with SPSS PROCESS 3.5 (Hayes, 2017) using Model 2 to account for two moderators (i.e., instrumental and emotional support). To examine how the two moderators interacted with each of the individual characteristics (i.e., math anxiety and math self-concept), two models were tested. The first model included math anxiety as the independent variable whereas the second model included math self-concept as the independent variable. In both models, instrumental and emotional support were specified as the moderators. Adolescent sex was also specified as the covariate as previous studies have indicated potential sex differences wherein boys tend to have better math achievement than girls (Mann \& DiPrete, 2016; Voyer \& Voyer, 2014). In cases where a significant interaction effect was observed, simple slope analyses were conducted as follow-up analyses based on Aiken and West (1991) to gain a more comprehensive understanding on the moderating effect. Specifically, PROCESS provides relevant values to divide participants into three groups that reflected low, medium, and high levels of teacher support. Math achievement could then be estimated by the coefficient of the predictor at each level of the moderator. In doing so, significant associations between student-related predictors and math achievement across different levels of teacher support would be evident.

\section{Results}

\subsection{Preliminary Analyses}

Assumptions underlying inferential statistics were first checked. Skewness and kurtosis scores revealed no issues with non-normality for both subsamples. Tests for multicollinearity indicated that a very low level of multicollinearity was present (VIF $=2.20$ for math self-concept, 1.27 for instrument support, 1.27 for emotional support, 2.14 for math anxiety) based on the cut-off of 10 (Neter, Kutner, Nachtsheim, \& Wasserman, 1996).

Table 1. Means, standard deviations, and intercorrelations among study variables

\begin{tabular}{lllllll}
\hline Variable & & 1 & 2 & 3 & 4 & 5 \\
\hline 1. & Math test score & 1.00 & & & & \\
\hline 2. & Math anxiety & $-.44^{* * *}$ & 1.00 & & & \\
\hline 3. & Math self-concept & $.50^{* * *}$ & $-.73^{* * *}$ & 1.00 & & \\
\hline 4. & Instrumental support & $.08^{* * *}$ & $-.13^{* * *}$ & $.19^{* * *}$ & 1.00 & \\
\hline 5. & Emotional Support & $.13^{* * *}$ & $-.13^{* * *}$ & $.20^{* * *}$ & $.45^{* * *}$ & 1.00 \\
\hline$M$ & & 509.42 & 2.38 & 2.63 & 3.22 & 3.13 \\
\hline$S D$ & & 84.87 & .75 & .81 & .61 & .53 \\
\hline
\end{tabular}

Note. ${ }^{*} p<.05, * * p<.01, * * * p<.001$

Correlational results are presented in Table 1. Composite scores were used to calculate the interrelations, and the means and the standard deviations were calculated with raw scores. As shown in Table 1, math anxiety and math 
self-concept yielded the strongest correlation, $r=-.73, p<.001$. The correlation between both instrumental support and emotional support was also relatively strong, $r=.45, p<.001$. Students' perceived math anxiety and math self-concept were also significantly correlated with teacher support. However, while math anxiety was negatively correlated with instrumental support, $r=-.13$, and emotional support, $r=-.13$, math self-concept was positively related to instrumental support $r=.19$, and emotional support, $r=.20, p \mathrm{~s}<.001$. With respect to math achievement, results indicated that while it was negatively correlated with math anxiety, $r=-.44$, it was positively correlated with math self-concept, $r=.50, p \mathrm{~s}<.001$. Lastly, there were moderate correlations between instrumental support and academic achievement, $r=.08$, as well as between emotional support and academic achievement, $r=.13, p \mathrm{~s}$ $<.001$.

\subsection{Moderation Effects of Teacher Support}

Table 2. Summary of moderation analyses for math anxiety

\begin{tabular}{|c|c|c|c|c|}
\hline \multirow[t]{2}{*}{ Variables } & \multirow[t]{2}{*}{$b$} & \multirow[t]{2}{*}{ S.E. } & \multirow{2}{*}{$\begin{array}{l}95 \% \\
\text { Lower C.I. }\end{array}$} & \multirow{2}{*}{$\begin{array}{l}95 \% \\
\text { Upper C.I. }\end{array}$} \\
\hline & & & & \\
\hline Sex & -1.25 & 1.28 & -3.76 & 1.26 \\
\hline Math anxiety & $-33.40 * * *$ & .63 & -34.64 & -32.15 \\
\hline Instrumental support & -1.20 & .68 & -2.54 & 0.14 \\
\hline Emotional support & $6.59 * * *$ & .70 & 5.22 & 8.00 \\
\hline Interaction of math anxiety and instrumental support & $-1.42 *$ & .58 & -2.56 & -0.27 \\
\hline Interaction of math anxiety and emotional support & -.61 & .60 & -1.77 & 0.56 \\
\hline
\end{tabular}

$* p<.05 . * * p<.01, * * * p<.001$

The model with math anxiety and teacher support as well as their interaction effects was significant after controlling adolescent sex, $F(6,13818)=596.69, p<.001, R^{2}=.21$. As indicated in Table 2, emotional support was a significant predictor after controlling for other predictors, No significant interaction effects was found between math anxiety and emotional support. By contrast, although instrumental support was not a significant predictor of math achievement after controlling for all predictors, there was a significant interaction effects between math anxiety and instrumental support. Specifically, the moderating effect of instrumental support on math anxiety and math achievement at low, medium, and high levels were respectively $b \mathrm{~s}=-32.34,-34.41,-36.47$, $p s<.001$ (see Figure 2). It appeared that instrumental support played a stronger role when math anxiety was low, but not when math anxiety was high.

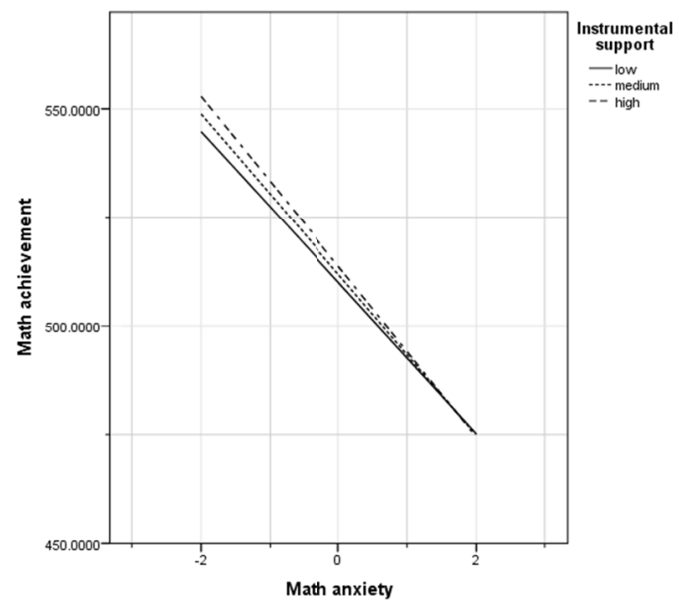

Figure 2. Simple slope analysis for the interaction effects between math anxiety and instrumental support on math achievement 
Table 3. Summary of moderation analyses for math self-concept

\begin{tabular}{|c|c|c|c|c|}
\hline \multirow[t]{2}{*}{ Variables } & \multirow[t]{2}{*}{$\bar{b}$} & \multirow[t]{2}{*}{ S.E. } & \multirow{2}{*}{$\begin{array}{l}95 \% \\
\text { Lower C.I. }\end{array}$} & \multirow{2}{*}{$\begin{array}{l}95 \% \\
\text { Upper C.I. }\end{array}$} \\
\hline & & & & \\
\hline Sex & $-2.82 *$ & 1.24 & -5.25 & -0.39 \\
\hline Math self-concept & $39.78 * * *$ & .62 & 38.56 & 41.00 \\
\hline Instrumental support & $-3.22 * * *$ & .67 & -.4 .53 & -1.91 \\
\hline Emotional support & $4.46^{* * *}$ & .69 & 3.10 & 5.83 \\
\hline Interaction of math self-concept and instrumental support & .15 & .58 & -0.99 & 1.29 \\
\hline Interaction of math self-concept and emotional support & -1.11 & $.59^{\dagger}$ & -2.26 & 0.05 \\
\hline
\end{tabular}

The model with math self-concept and teacher support as well as their interaction effects was significant after controlling for adolescent sex, $F(6,13818)=796.01, R^{2}=.26, p<.001$. As presented in Table 3 , instrumental and emotional support was both significant predictors of math achievement after controlling for all predictors. However, no significant interaction effects were found between math self-concept and instrumental support, as well as between math self-concept and emotional support.

\section{Discussion}

The purpose of the present study was to examine the extent to which math anxiety/math self-concept and teacher support (i.e., instrumental and emotional support) predicted math achievement. Potential moderating effects of teacher support on math anxiety/math self-concept were also examined. Furthermore, adolescent sex was treated as a covariate. The results partially supported an association between student-related factors and math achievement, as well as teacher-related variables and math achievement. Moreover, instrumental support emerged as the only significant moderator in the association between math anxiety and math achievement.

Consistent with previous research (e.g., Foley et al., 2017), math anxiety was negatively associated with math achievement, suggesting that students with higher math anxiety are likely to have lower math scores. Under this model, emotional support, but not instrument support, was positively and significantly associated with math achievement. These findings suggest that emotional support might play a stronger role than instrumental support in its relation to math achievement when math anxiety was controlled. These findings are consistent with a large body of research that has consistently emphasized the importance of teacher emotional support in fostering students' academic engagement (e.g., Green et al., 2008). Interestingly, instrumental support, but not emotional support, interacted with math anxiety to predict math achievement. Specifically, simple slope analysis suggests that students tend to have higher math achievement when they receive high instrumental support in face of low math anxiety. However, the moderating role of instrument support seems to be mitigated at high level of math anxiety, wherein students with high math anxiety are likely to have lower math achievement regardless of the level of instrument support. These findings suggest that there might be a threshold to the role of instrumental support, emphasizing the importance for teachers to be aware of the teaching methods they are utilizing in the classroom in order to avoid contributing to harmful effects and attitudes around math, and their negative, long-term side effects. Bieg and colleagues (2017) pointed to pair/small-group work as a helpful alternative to direct instruction when working with particularly anxious students, and these methods have been associated with higher student engagement and fostering emotions that are conducive to learning. This interaction effect underlines the need for scholars and educational administrators to carefully consider individual student factors (e.g., math anxiety) in relation with different types of teacher support in order to better understand its role in learning.

Math self-concept was positively associated with math achievement after controlling for both forms of teacher support and adolescent sex, providing further empirical support for the reciprocal association that exists between math self-concept and math-anxiety (Ahmed, Minnaert, Kuyper \& van der Werf, 2012). Under this model, instrumental support was negatively associated whereas emotional support was positively associated with math achievement. Although these findings are inconsistent with previous studies that have identified instrumental support as a positive correlate of math achievement (Tennant et al., 2015; Wong et al., 2018), they are consistent with those indicating that emotional support would be positively associated with math achievement and student attitudes conducive to academic success (e.g., Lazarides \& Buchholz, 2019). A plausible explanation for the negative role of instrumental support is that students might interpret instrumental support as a sign for their 
incompetence, which have an inadvertent negative impact on math achievement. In support of this explanation, students who feel less competent towards math tend to have poorer math outcomes (Parker et al., 2014; Sakiz, 2015). Further research on potential mediators (e.g., math self-efficacy) in the association between instrumental support and math achievement is needed.

Contradicting the hypothesis, neither instrumental nor emotional support interacted with math self-concept to predict math achievement. These findings imply that math self-concept might be a particular strong predictor of math achievement, wherein students who position themselves highly in the domain of math are likely to have better achievement regardless of how much instrument and emotional support they receive from teachers. In this contention, math self-concept has a beta-weight that is substantially larger than that of instrumental support, even after controlling for the variances accounted by this form of support and sex differences. Given the paucity of studies examining the moderating effects of instrumental support on adolescents' academic outcomes, further research is needed to elucidate the extent to which the association between math self-concept and math achievement differs at different levels of instrumental and emotional support.

\subsection{Limitations and Future Directions}

Several limitations need to be considered. First, the cross-sectional and correlational nature of this study precludes causal interpretations. For example, it is unclear whether students' math self-concept leads to academic performance or vice versa. Given that there could be a potential bi-directional association between math anxiety and poor achievement (Carey, Hill, Devine, \& Szücs, 2016; Ma \& Xu, 2004), as well as between academic self-concept and math achievement (Chen et al., 2013), longitudinal studies are needed to discern how different types of teacher support moderate changes in students' math anxiety and math self-concept and their relations to math performance over time. Similarly, quasi-experimental studies are needed to better assess variations and effects of teacher support on the roles of math self-concept and math anxiety on academic performance. Second, given that the present study focused exclusively on Canadian students, it would be important for future studies to consider for potential cultural differences. For instance, the association between academic self-concept and achievement could become less clear in countries where students might endorse low academic self-concept despite being high achievers (Marsh \& Parker, 1984). Third, given that this study relied on students' self-reports, future studies would benefit from adopting a multi-informant approach. Relatedly, measures that provide a more comprehensive assessment on the variables of interest are needed. For example, although measures of instrumental and emotional support pertain to students' actual math teachers, math achievement was measured by students' achievement on the PISA assessment; accordingly, it would be important to account for actual math achievement as reflected through actual school grades. Lastly, this study focused solely on teacher support and its moderating role on math outcomes. Given that adolescence represents a time when peers become increasingly important and that peer support has been associated with academic outcomes (Wentzel et al., 2016), it would be interesting to also consider the moderating role of peer support.

In spite of these limitations, this study has several strengths. By accounting for not only instrumental, but also emotional support, this study contributes to the limited literature on the moderating of teacher support. Moreover, by contextualizing this examination within the context of math learning, this study advances the limited understanding on how teacher support interacts with individual characteristics to promote math achievement. Furthermore, this study adds to extant studies that have mainly examined teacher support among preschool and elementary students with its focus on middle-school students.

\subsection{Implications}

Findings of the current study may have important implications for teacher training and professional development. First, in view that students with low math anxiety tend to achieve better when they receive high levels of instrumental support, it would be important for school practitioners to maximize the amount of learning support that these students receive. To the extent that this provision is difficult to achieve due to reasons such as high student-teacher ratio, encouraging students to support each other in their math learning might be a useful alternative. In support of this, systematic reviews on various math programs indicated that cooperative learning (e.g., peer tutoring, student discussions) is positively associated with math skills such as computation, conceptual understanding and problem-solving among both primary and secondary students (Robinson, Schofield, \& Steers-Wentzell, 2005; Slavin, Lake, \& Groff, 2009).

Second, given that emotional support was positively associated with math achievement even after controlling for instrumental support and math self-concept/math anxiety, supporting teachers in communicating emotional support to students is important. Indeed, the emerging literature on school climate suggests that students have better achievement in subjects such as math and reading when they learn in a classroom that is characterized by 
nurturing student-teacher relationship, high levels of teacher sensitivity to student needs, and activities that encourage self-expressions and opinions (Reyes, Brackett, Rivers, White, \& Salovey, 2012; Rudasill et al., 2010). In other words, it is important for school practitioners to embed emotionally supportive relationships into academic support so as to facilitate better math achievement (McCormick \& O'Connor, 2015). This is especially critical considering that secondary students tend to have less opportunities to establish affective relationships with their teacher due to larger student-teacher ratio. Furthermore, as teachers often receive little training in how to create emotionally supportive relationships with their students (Hughes \& Kwok, 2007), there is a need for educators to reform the teaching curriculum so as to instill pre-service teachers with relevant competencies. Further, in-service teachers would benefit from professional training opportunities

Taken together, the present study not only points to the importance to consider math achievement in relation to cognitive variables including math anxiety and self-concept, but also highlights the need to account for the unique and important roles of different types of teacher support in promoting the students' school success.

\section{Acknowledgements}

This study utilised a secondary dataset provided by the Organization for Economic Co-Operation and Development for the 2012 Program for International Student Assessment (PISA). The dataset was limited to data collected in Canada.

The authors have no conflicts to report. The author(s) received no financial support for the research.

\section{References}

Ahmed, W., Minnaert, A., Kuyper, H., \& Van Der Werf, G. (2012). Reciprocal relationships between math self-concept and math anxiety. Learning and Individual Differences, 22(3), 385-389. https://doi.org/10.1016/j.lindif.2011.12.004

Aiken, L. S., \& West, S. G. (1991). Multiple regression: Testing and interpreting interactions. Newbury Park, CA: Sage.

Anderton, R., Joyce, C., \& Hine, G. (2017). Secondary school mathematics and science matters: Academic performance for secondary students transitioning into university allied health and science courses. International Journal of Innovation in Science and Mathematics Education, 25(1), 34-47.

Ashcraft, M. H., \& Moore, A. M. (2009). Mathematics anxiety and the affective drop in performance. Journal of Psychoeducational Assessment, 27(3), 197-205. https://doi.org/10.1177/0734282908330580

Baron, R. M., \& Kenny, D. A. (1986). The moderator-mediator variable distinction in social psychological research: Conceptual, strategic, and statistical considerations. Journal of Personality and Social Psychology, 51(6), 1173-1182.

Bieg, M., Goetz, T., Sticca, F., Brunner, E., Becker, E., Morger, V., \& Hubbard, K. (2017). Teaching methods and their impact on students' emotions in mathematics: An experience-sampling approach. The International Journal on Mathematics Education, 49(3), 411-422. https://doi.org/10.1007/s11858-017-0840-1

Birch, S., \& Ladd, G. W. (1998). Children's interpersonal behaviors and the teacher-child relationship. Developmental Psychology, 34, 934-946. https://doi.org/10.1037/0012-1649.34.5.934

Bong, M., \& Skaalvik, E. M. (2003). Academic self-concept and self-efficacy: How different are they really?. Educational Psychology Review, 15(1), 1-40. https://doi.org/10.1023/A:1021302408382

Brunner, M., Keller, U., Hornung, C., Reichert, M., \& Martin, R. (2009). The cross-cultural generalizability of a new structural model of academic self-concepts. Learning and Individual Differences, 19, 387-403. https://doi.org/10.1016/j.lindif.2008.11.008

Carey, E., Hill, F., Devine, A., \& Szücs, D. (2016). The chicken or the egg? The direction of the relationship between mathematics anxiety and mathematics performance. Frontiers in Psychology, 6. https://doi.org/10.3389/fpsyg.2015.01987

Chen, S. K., Yeh, Y. C., Hwang, F. M., \& Lin, S. S. (2013). The relationship between academic self-concept and achievement: A multicohort-multioccasion study. Learning and Individual Differences, 23, 172-178. https://doi.org/10.1016/j.lindif.2012.07.021

Duncan, G. J., Dowsett, C. J., Claessens, A., Magnuson, K., Huston, A. C., Klebanov, P., ... Japel, C. (2007). School readiness and later achievement. Developmental Psychology, 43(6), 1428-1446. https://doi.org/10.1037/0012-1649.43.6.1428 
Eccles, J. S., \& Roeser, R. W. (2009). Schools, academic motivation, and stage-environment fit. Handbook of Adolescent Psychology. New York: Wiley Publishing.

Federici, R. A., \& Skaalvik, E. M. (2014a). Students' perceptions of emotional and instrumental teacher support: Relations with motivational and emotional responses. International Education Studies, 7(1), 21-36. https://doi.org/10.5539/ies.v7n1p21

Federici, R. A., \& Skaalvik, E. M. (2014b). Students' perception of instrumental support and effort in mathematics: The mediating role of subjective task values. Social Psychology of Education, 17(3), 527-540. https://doi.org/10.1007/s11218-014-9264-8

Foley, A. E., Herts, J. B., Borgonovi, F., Guerriero, S., Levine, S. C., \& Beilock, S. L. (2017). The math anxiety-performance link. Current Directions in Psychological Science, 26(1), 52-58. https://doi.org/10.1177/0963721416672463

Furrer, C., \& Skinner, E. (2003). Sense of relatedness as a factor in children's academic engagement and $\begin{array}{lllll}\text { performance. Journal of Educational Psychology, } & \text { 95(1), 148-162. }\end{array}$ https://doi.org/10.1037/0022-0663.95.1.148

Gherasim, L. R., Butnaru, S., \& Mairean, C. (2013). Classroom environment, achievement goals and maths

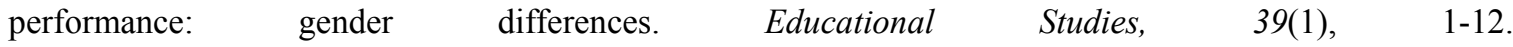
https://doi.org/10.1080/03055698.2012.663480

Goetz, T., Lüdtke, O., Nett, U. E., Keller, M. M., \& Lipnevich, A. A. (2013). Characteristics of teaching and students' emotions in the classroom: Investigating differences across domains. Contemporary Educational Psychology, 38(4), 383-394. https://doi.org/10.1016/j.cedpsych.2013.08.001

Green, G., Rhodes, J., Hirsch, A. H., Suárez-Orozco, C., \& Camic, P. M. (2008). Supportive adult relationships and the academic engagement of Latin American immigrant youth. Journal of School Psychology, 46(4), 393-412. https://doi.org/10.1016/j.jsp.2007.07.001

Gregor, A. (2005). Examination anxiety live with it, control it or make it work for you?. School Psychology International, 26(5), 617-635. https://doi.org/10.1177/0143034305060802

Griggs, M. S., Gagnon, S. G., Huelsman, T. J., Kidder-Ashley, P., \& Ballard, M. (2009). Student-teacher relationships matter: Moderating influences between temperament and preschool social competence. Psychology in the Schools, 46(6), 553-567. https://doi.org/10.1002/pits.20397

Griggs, M. S., Rimm-Kaufman, S. E., Merritt, E. G., \& Patton, C. L. (2013). The Responsive Classroom approach and fifth grade students' math and science anxiety and self-efficacy. School Psychology Quarterly, 28(4), 360-373. https://doi.org/10.1037/spq0000026

Guo, J., Marsh, H. W., Parker, P. D., Morin, A. J., \& Yeung, A. S. (2015). Expectancy-value in mathematics, gender and socioeconomic background as predictors of achievement and aspirations: A multi-cohort study. Learning and Individual Differences, 37, 161-168. https://doi.org/10.1016/j.lindif.2015.01.008

Hamre, B. K., \& Pianta, R. C. (2005). Can instructional and emotional support in the first-grade classroom make a difference for children at risk of school failure?. Child Development, 76(5), 949-967. https://doi.org/10.1111/j.1467-8624.2005.00889.x

Hayes, A. F. (2017). Introduction to mediation, moderation, and conditional process analysis: A regression-based approach. Guilford Publications.

Hindman, A., Skibbe, L., Miller, A., \& Zimmerman, M. (2010). Ecological contexts and early learning: Contributions of child, family, and classroom factors during head start, to literacy and mathematics growth through first grade. Early Childhood Research Quarterly, 25, 235-250. https://doi.org/10.1016/j.ecresq.2009.11.003

Hochweber, J., \& Vieluf, S. (2018). Gender differences in reading achievement and enjoyment of reading: The role of perceived teaching quality. Journal of Educational Research, 111(3), 268-283. https://doi.org/10.1080/00220671.2016.1253536

Hughes, J., \& Kwok, O. M. (2007). Influence of student-teacher and parent-teacher relationships on lower achieving readers' engagement and achievement in the primary grades. Journal of Educational Psychology, 99(1), 39-51.

Joyce, C., Hine, G., \& Anderton, R. (2017). The association between secondary mathematics and first year university performance in health sciences. Issues in Educational Research, 27(4), 770-783. Retrieved from 
http://www.iier.org.au/iier27/joyce.pdf

Kikas, E., \& Mägi, K. (2016). Does self-efficacy mediate the effect of primary school teachers' emotional support on learning behavior and academic skills?. Journal of Early Adolescence, 36, 1-35. https://doi.org/10.1177/0272431615624567

Konishi, C., \& Hymel, S. (2009). Bullying and stress in early adolescence the role of coping and social support. Journal of Early Adolescence, 29(3), 333-356. https://doi.org/10.1177/0272431608320126

Konishi, C., Hymel, S., Zumbo, B. D., \& Li, Z. (2010). Do school bullying and student-teacher relationships matter for academic achievement? A multilevel analysis. Canadian Journal of School Psychology, 25, 19-39. https://doi.org/10.1177/0829573509357550

Lazarides, R., \& Buchholz, J. (2019). Student-perceived teaching quality: How is it related to different achievement emotions in mathematics classrooms?. Learning and Instruction, 61, 45-59. https://doi.org/10.1016/j.learninstruc.2019.01.001

Lopez, F. A. (2012). Moderators of language acquisition models and reading achievement for English language learners: The role of emotional warmth and instructional support. Teachers College Record, 114(8), 1-30.

Loukas, A., \& Robinson, S. (2004). Examining the moderating role of perceived school climate in early adolescent adjustment. Journal of Research on Adolescence, 14, 209-233. https://doi.org/10.1111/j.1532-7795.2004.01402004.x

Loukas, A., Roalson, L. A., \& Herrera, D. E. (2010). School connectedness buffers the effects of negative family relations and poor effortful control on early adolescent conduct problems. Journal of Research on Adolescence, 20(1), 13-22. https://doi.org/10.1111/j.1532-7795.2009.00632.x

Ma, X. (2003). Sense of belonging to school: Can schools make a difference?. Journal of Educational Research, 96, 340-349. https://doi.org/10.2307/749772

Ma, X., \& Xu, J. (2004). The causal ordering of mathematics anxiety and mathematics achievement: a longitudinal panel analysis. Journal of Adolescence, 27(2), 165-179. https://doi.org/10.1016/j.adolescence.2003.11.003

Maloney, E. A., \& Beilock, S. L. (2012). Math anxiety: Who has it, why it develops, and how to guard against it. Trends in Cognitive Sciences, 16(8), 404-406. https://doi.org/10.1016/j.tics.2012.06.008

Mann, A., \& DiPrete, T. A. (2016). The consequences of the national math and science performance environment for gender differences in STEM aspiration. Sociological Science, 3, 568-603. https://doi.org/10.15195/v3.a25

Marsh, H. W., \& Parker, J. W. (1984). Determinants of student self-concept: Is it better to be a relatively large fish in a small pond even if you don't learn to swim as well?. Journal of Personality and Social Psychology, 47(1), 213-231. https://doi.org/10.1037/0022-3514.47.1.213

Marsh, H. W., Trautwein, U., Lüdtke, O., Köller, O., \& Baumert, J. (2005). Academic self-concept, interest, grades, and standardized test scores: Reciprocal effects models of causal ordering. Child Development, 76(2), 397-416.

McCormick, M. P., \& O'Connor, E. E. (2015). Teacher-child relationship quality and academic achievement in elementary school: Does gender matter?. Journal of Educational Psychology, 107(2), 502-516. https://doi.org/10.1037/a0037457

McDonough, I. M., \& Gerardo, R. (2018). Individual differences in math anxiety and math self-concept promote forgetting in a directed forgetting paradigm. Learning and Individual Differences, 64, 33-42. https://doi.org/10.1016/j.lindif.2018.04.007

Midgley, C., Feldlaufer, H., \& Eccles, J. S. (1989). Student/teacher relations and attitudes toward mathematics before and after the transition to junior high school. Child Development, 60(4), 981-992. https://doi.org/10.2307/1131038

Neter, J., Kutner, M. H., Nachtsheim, C. J., \& Wasserman, W. (1996). Applied linear statistical models.

Núñez-Peña, M. I., Suárez-Pellicioni, M., \& Bono, R. (2012). Effects of math anxiety on student success in higher education. International Journal of Educational Research, 36-43. https://doi.org/10.1016/j.ijer.2012.12.004

OECD. (2013). PISA 2012 Assessment and Analytical Framework: Mathematics, Reading, Science. Problem 
Solving and Financial Literacy. OECD Publishing. https://doi.org/10.1787/9789264190511-en

OECD. (2104). PISA 2012 Technical Report. OECD Publishing. Retrieved from https://www.oecd.org/pisa/pisaproducts/PISA-2012-technical-report-final.pdf

Organization for Economic Co-operation and Development. (2013). PISA 2012 results: Ready to learn: Students ' engagement, drive and self-beliefs (Vol. III). Paris, France: Author. https://doi.org/10.1787/9789264201170-en

Osterman, K. (2000). Students' need for belonging in the school community. Review of Educational Research, 70, 323-367. https://doi.org/10.3102/00346543070003323

Parker, P. D., Marsh, H. W., Ciarrochi, J., Marshall, S., \& Abduljabbar, A. S. (2014). Juxtaposing math self-efficacy and self-concept as predictors of long-term achievement outcomes. Educational Psychology, 34(1), 29-48. https://doi.org/10.1080/01443410.2013.797339

Parker, P. D., Schoon, I., Tsai, Y.-M., Nagy, G., Trautwein, U., \& Eccles, J. S. (2012). Achievement, agency, gender, and socioeconomic background as predictors of postschool choices: A multicontext study. Developmental Psychology, 48(6), 1629-1642. https://doi.org/10.1037/a0029167

Patrick, H., Ryan, A. M., \& Kaplan, A. (2007). Early adolescents' perceptions of the classroom social environment, motivational beliefs, and engagement. Journal of Educational Psychology, 99, 83-98. https://doi.org/10.1037/0022-0663.99.1.83

Pedhazur, E. J. (1997). Multiple regression in behavioral research (3rd ed.). Orlando, FL: Harcourt Brace.

Reyes, M. R., Brackett, M. A., Rivers, S. E., White, M., \& Salovey, P. (2012). Classroom emotional climate, student engagement, and academic achievement. Journal of Educational Psychology, 104(3), 700-712. https://doi.org/10.1037/a0027268

Reyna, V. F., Nelson, W. L., Han, P. K., \& Dieckmann, N. F. (2009). How numeracy influences risk comprehension and medical decision making. Psychological Bulletin, 135(6), 943-973. https://doi.org/10.1037/a0017327

Ritchie, S. J., \& Bates, T. C. (2013). Enduring links from childhood mathematics and reading achievement to

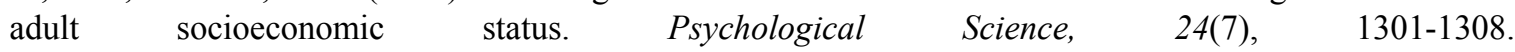
https://doi.org/10.1177/0956797612466268

Robinson, D. R., Schofield, J. W., \& Steers-Wentzell, K. L. (2005). Peer and cross-age tutoring in math: Outcomes and their design implications. Educational Psychology Review, 17, 327-362. https://doi.org/10.1007/s10648-005-8137-2

Romano, E., Babchishin, L., Pagani, L. S., \& Kohen, D. (2010). School readiness and later achievement: replication and extension using a nationwide Canadian survey. Developmental Psychology, 46(5), 995-1007. https://doi.org/10.1037/a0018880

Roorda, D. L., Jak, S., Zee, M., Oort, F. J., \& Koomen, H. M. (2017). Affective teacher-student relationships and students' engagement and achievement: A meta-analytic update and test of the mediating role of engagement. School Psychology Review, 46(3), 239-261. https://doi.org/10.17105/SPR-2017-0035.V46-3

Rudasill, K. M., Gallagher, K. C., \& White, J. M. (2010). Temperamental attention and activity, classroom emotional support, and academic achievement in third grade. Journal of School Psychology, 48(2), 113-134. https://doi.org/10.1016/j.jsp.2009.11.002

Ruzek, E. A., Hafen, C. A., Allen, J. P., Gregory, A., Mikami, A. Y., \& Pianta, R. C. (2016). How teacher emotional support motivates students: The mediating roles of perceived peer relatedness, autonomy support, and competence. Learning and Instruction, 42, 95-103. https://doi.org/10.1016/j.learninstruc.2016.01.004

Sakiz, G. (2015). Perceived teacher factors in relation to students' achievement- related outcomes in science classrooms in elementary school. European Journal of Science and Mathematics Education, 3(2), 115-129.

Sakiz, G., Pape, S. J., \& Hoy, A. W. (2012). Does perceived teacher affective support matter for middle school students in mathematics classrooms?. Journal of School Psychology, 50, 235-255. https://doi.org/10.1016/j.jsp.2011.10.005

Semmer, N. K., Elfering, A., Jacobshagen, N., Perrot, T., Beehr, T. A., \& Boos, N. (2008). The emotional meaning of instrumental social support. International Journal of Stress Management, 15(3), 235-251. Retrieved from http://www.statcan.gc.ca/pub/71-222-x/2008001/sectionf/f-dropout-abandon-eng.htm 
Skaalvik, E. M., \& Skaalvik, S. (2004). Self-concept and self-efficacy: A test of the internal/external frame of reference model and predictions of subsequent motivation and achievement. Psychological Reports, $95(3$ suppl), 1187-1202. https://doi.org/10.2466/pr0.95.3f.1187-1202

Slavin, R. E., Lake, C., \& Groff, C. (2009). Effective programs in middle and high School mathematics: A best-evidence synthesis. Review of Educational Research, 79(2), 839-911.

Song, J., Bong, M., Lee, K., \& Kim, S. (2015). Longitudinal investigation into the role of perceived social support in adolescents' academic motivation and achievement. Journal of Educational Psychology, 107(3), 821-841. https://doi.org/10.1037/edu0000016

Strati, A. D., Schmidt, J. A., \& Maier, K. S. (2017). Perceived challenge, teacher support, and teacher obstruction as predictors of student engagement. Journal of Educational Psychology, 109(1), 131-147.

Tennant, J. E., Demaray, M. K., Malecki, C. K., Terry, M. N., Clary, M., \& Elzinga, N. (2015). Students' ratings of teacher support and academic and social-emotional well-being. School Psychology Quarterly, 30(4), 494-512. https://doi.org/10.1037/spq0000106

Valiente, C., Swanson, J., \& Eisenberg, N. (2012). Linking students' emotions and academic achievement: When and why emotions matter. Child Development Perspectives, 6(2), 129-135. https://doi.org/10.1111/j.1750-8606.2011.00192.x

Voyer, D., \& Voyer, S. D. (2014). Gender differences in scholastic achievement: A meta-analysis. Psychological Bulletin, 140(4), 1174-1204. https://doi.org/10.1037/a0036620

Vukovic, R. K., Kieffer, M. J., Bailey, S. P., \& Harari, R. R. (2013). Mathematics anxiety in young children: Concurrent and longitudinal associations with mathematical performance. Contemporary Educational Psychology, 38(1), 1-10. https://doi.org/10.1016/j.cedpsych.2012.09.001

Wang, M. T., Brinkworth, M., \& Eccles, J. (2013). Moderating effects of teacher-student relationship in adolescent trajectories of emotional and behavioral adjustment. Developmental Psychology, 49(4), 690-705. https://doi.org/10.1037/a0027916

Wentzel, K. R., Russell, S., \& Baker, S. (2016). Emotional support and expectations from parents, teachers, and peers predict adolescent competence at school. Journal of Educational Psychology, 108(2), 242-255. https://doi.org/10.1037/edu0000049

Wong, T. K. Y., Tao, X., \& Konishi, C. (2018). Teacher support in learning: Instrumental and appraisal support in relation to math achievement. Issues in Educational Research, 28(1), 202-219.

Wu, S., Amin, H., Barth, M., Malcarne, V., \& Menon, V. (2012). Math anxiety in second and third graders and its relation to mathematics achievement. Frontiers in Psychology, 3, 1-11. https://doi.org/10.3389/fpsyg.2012.00162

Yu, R., \& Singh, K. (2018). Teacher support, instructional practices, student motivation, and mathematics achievement in high school. Journal of Educational Research, 111(1), 81-94. https://doi.org/10.1080/00220671.2016.1204260

\section{Copyrights}

Copyright for this article is retained by the author(s), with first publication rights granted to the journal.

This is an open-access article distributed under the terms and conditions of the Creative Commons Attribution license (http://creativecommons.org/licenses/by/4.0/). 